\title{
Malign Melanoma with Bone Marrow Involvement: A Case Report
}

\section{Kemik İliği Tutulumu ile Giden Malign Melanom: Olgu Sunumu}

\author{
İbrahim YILDIRIM ${ }^{1}$, Özcan Sayglı ${ }^{1}$, AYŞE TEMIZEL TAŞLI ${ }^{1}$, Nurbuke Sarkisla ${ }^{1}$, Sedef \\ ÇAKAR ${ }^{1}$, Eşref Oğuz Güven², Fisun Ardic Yukruk³ ${ }^{3}$ Ömer Canpolat ${ }^{4}$ \\ ${ }^{1}$ Sağlık Bilimleri Üniversitesi Tıp Fakültesi, Ankara Dr Abdurrahman Yurtaslan Onkoloji Eğitim ve Araştırma \\ Hastanesi, Onkoloji EAH Dâhiliye Kliniği Ankara, Türkiye \\ ${ }^{2}$ Sağlık Bilimleri Üniversitesi Tıp Fakültesi, Ankara Dr Abdurrahman Yurtaslan Onkoloji Eğitim ve Araştırma \\ Hastanesi, Onkoloji EAH Üroloji Kliniği Ankara, Türkiye \\ ${ }^{3}$ Sağlık Bilimleri Üniversitesi Tıp Fakültesi, Ankara Dr Abdurrahman Yurtaslan Onkoloji Eğitim ve Araştırma \\ Hastanesi, Onkoloji EAH Patoloji Bölümü Ankara, Türkiye \\ ${ }^{4}$ Elazığ Fethi Sekin Şehir Hastanesi Acil Tıp Bölümü, Elazı̆̆g, Türkiye
}

Dergiye Ulaşma Tarihi: 09.05.2019 Dergiye Kabul Tarihi: 10.07.2019 Doi: 10.5505/aot.2019.46330

\section{ÖZET}

Nodüler tip malign melanom nadir görülen bir malign melanom alt tipidir. S1klıkla ileri evrede tanı alır ve kötü prognozludur. Bu olgu sunumunda nadir olarak rastlanan, karakteristik cilt bulguları olan, kemik iliği tutulumu ve yaygın damar içi pıhtılaşma tablosunun bir arada bulunduğu bir nodüler tip malign melanom vakası sunuyoruz. Anahtar Kelimeler: Metastatik malign melanom, Nodüler melanom, kemik iliği tutulumu, intravasküler hemoliz, yaygın damar içi pıhtılaşma

\section{ABSTRACT}

Nodular type malignant melanoma a rare subtype of malignant melanoma with poor prognosis. It is often diagnosed at advanced stage. In this case report, we present a metastatic malign melanom case with bone marrow involvement and dissemine intravascular haemolysis.

Keywords: Metastatic malign melanom, nodular type melanoma, bone marrow involvement, dissemine intravascular haemolysis

\section{GíRiş}

Melanom nöral yarık kökenli melanositlerden ve melanositlerin farklılaşması sonucu oluştuğu düşünülen nevüs hücrelerinden kaynaklanan bir tümördür. Bütün kanser ölümlerinin \%1,2'lik kısmını oluşturmaktadır (1) ve sıklığı giderek artmaktadır (2). Ortanca görülme yaşı 60-63 olmasina rağmen alt tiplerine göre değişmektedir (3). En sik metastaz yaptı̆̆ 1 organsantral sinir sistemi ve akciğerdir (4). Metastatik malign melanomda kemik iliği tutulumu ise \%20-24 oranındadır(4). Anatomik lokalizasyona, tümörün büyüme ve histopatolojik tipine göre dört ana tip tanımlanmıştır. En sık yüzeyel yayılan tip görülürken daha sonra sirasılya, nodüler, lentigo ve akral lentiginöz malign melanom gelmektedir (3-5).Nodüler tip \%15'lik oranla malign melanomikinci en s1k görülen alt tiptirve erkeklerde daha siktır (6). Biz bu raporda; 58 yaşında, hemolitik anemi, kemik iliği tutulumu olan ve yaygın damar içi pıhtılaşması ile yaşamını yitiren bir hasta sunmaktayız.

\section{OLGU SUNUMU}

Elli sekiz yaşında erkek hasta, son bir hafta içerisinde ortaya çıkan vücutta yaygın morarmalar, ara ara kısa süreli tek bir noktaya bakma ve halsizlik şikâyetleriyle başvurduğu acil servisten, anemi, trombositopeni, myoklonik nöbet tanılarıyla kliniğimize yatırıldı. Daha önce bilinen bir hastalık ve nöbet 
öyküsü yoktu. Hastanın tıbbi sorgusunda yakın tarihte böbrek üstü bezinde kitle tespit edildiği, 20 gün önce nefes darlığ 1 nedeniyle başka bir doktora gittiği ve tedavi gördüğü, onbeş gün önce surt bölgesindeki nevüs nedeniyle dermatoloji polikliniğine başvurduğu ve o lezyondan biyopsi yapıldı̆̆ı öğrenildi. Soy geçmişinde bir özellik bulunmamaktaydı. Hastanın her iki kolunda proksimal parmak eklemlerinden başlayan tüm ön kolu kaplayan dirsek eklemi geçen ekimozu, sol bacak ön yüzünde $5 \times 10 \mathrm{~cm}$ boyutunda ekimozu mevcuttu. Konjunktivaları soluk, mukozaları kuru, solunum sesleri doğal, batın rahat, ense sertliği yoktu. Ateş: $36,1^{\circ} \mathrm{C}$, nabız: $120 /$ dak, kan basinc1: $120 / 75 \mathrm{mmHg}$, oksijen saturasyonu: \%98 idi. Yapılan kan sayımında lökositoz, hemolitik anemi, trombositopeni, kanama zamanı uzaması, fibrinojen düşüklüğü, d-dimer artışı saptandı. Laboratuvar sonuçları tablo 1 'de gösterilmiştir. Çekilen abdomen tomografisinde mediyastanel ve hiler alanlarda 9 milimetre boyutlarında lenfadenopati, her iki aksillada multiple lenfadenopati, plevral kalınlaşma, yer yer nodüler dansite artışı ve sol surrenal 15×22 mm'lik bir lezyonu vard. Beyin tomografisi ve manyetik rezonans görüntüleme tetkiklerinde metastaz bulgusu tespit edilmedi. Yoğun bakım izlemlerinde bisitopeni etiyolojisine yönelik olarak kemik iliği biyopsisi yapıldı. Sonuç; -malign melanom infiltrasyonu gösteren kemik iliği- şeklinde raporlandı (Şekil 1). Bu arada ayaktan yapılan nevüs biyopsi sonucu da "nodüler tip malign melanom" olarak geldi (Şekil 2-6).

Tablo 1. Yatış günü laboratuar sonuçları

\begin{tabular}{lll}
\hline TEST & $\begin{array}{l}\text { HASTA } \\
\text { SONUCU }\end{array}$ & $\begin{array}{l}\text { REFERANS } \\
\text { ARALIĞI }\end{array}$ \\
\hline Lökosit & $26,9 \times 10^{3} / \mu \mathrm{L}$ & $4-10$ \\
Hemoglobin & $9,46 \mathrm{~g} / \mathrm{dL}$ & $11,5-16$ \\
Trombosit & $30 \times 10^{3} / \mu \mathrm{L}$ & $100-300$ \\
Protrombin & $20 \mathrm{sn}$ & $10-15$ \\
zaman1 & & \\
aPTT & $32 \mathrm{sn}$ & $22-34$ \\
INR & $1,8 \%$ & $0,8-1,2$ \\
Fibrinojen & $30 \mathrm{mg} / \mathrm{dL}$ & $150-400$ \\
LDH & $29789 \mathrm{U} / \mathrm{L}$ & $0-247$ \\
D-Dimer & $80000 \mathrm{ng} / \mathrm{mL}$ & $0-500$ \\
Retikülosit & $\% 3$ & $0,3-2,4$ \\
Haptoglobin & $8 \mathrm{mg} / \mathrm{dl}$ & $30-200$ \\
\hline
\end{tabular}

Adress for correspondence: Ankara Onkoloji EAH, İç Hastalıkları Ankara - Türkiye e-mail: ibal@ttmail.com

Available at www.actaoncologicaturcica.com

Copyright $\odot$ Ankara Onkoloji Hastanesi
INR: International normalizing ratio, aPTT: aktivated partial thromboplastin time, LDH: Laktat dehidrogenaz

Hastaya destek tedavilerinin yanı sira primer hastalığına yönelik olarak böbrek yetmezliği nedeniyle $\% 40$ doz redüksiyonu yapılarak dakarbazin, 5 gün süreyle verildi. 1 hafta sonra genel durumu kötüleşen hasta yaygın damar içi pıtıtışma nedeniyle, planlanan nivolumab tedavisini alamadan eksitus oldu.

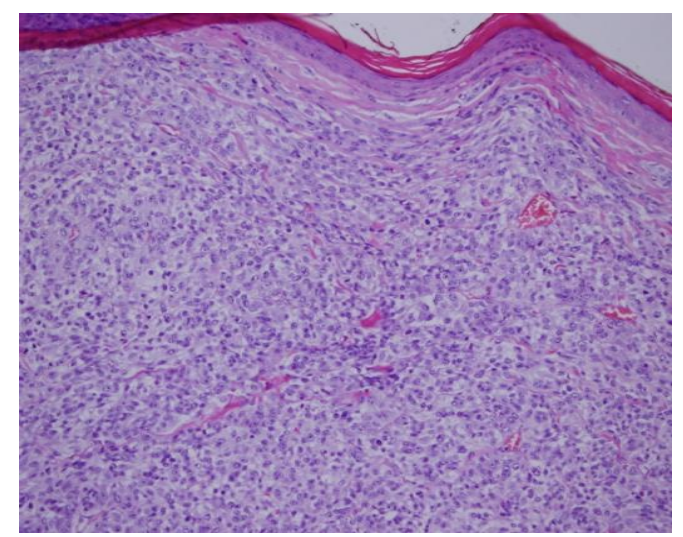

Şekil 1. Dermal tabanlı melanositik tümör (HEx200)

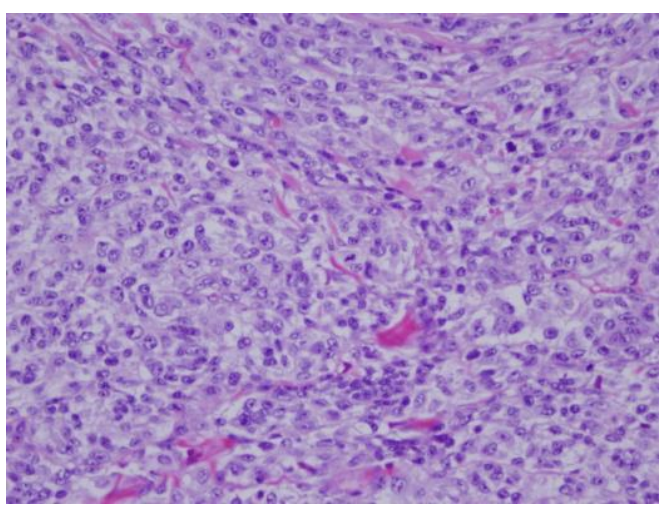

Şekil 2. Sitolojik olarak malign hücreler HE X400

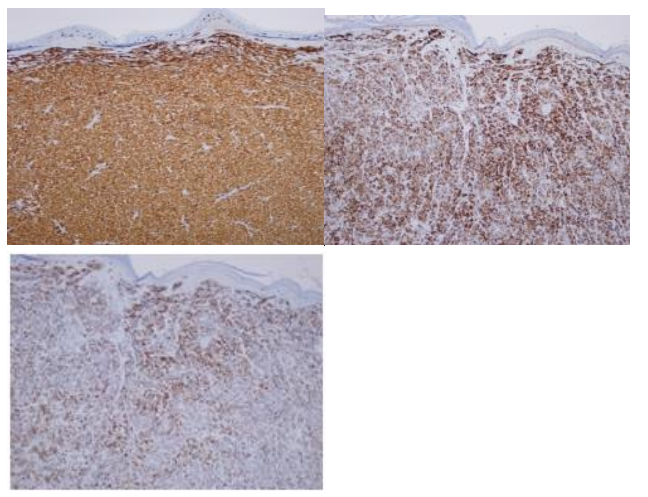

Şekil 4,5,6. Tümör hücrelerinde S100, HMB45, Melan A ve Tirozin ile immünhistokimyasal çalışmalar 


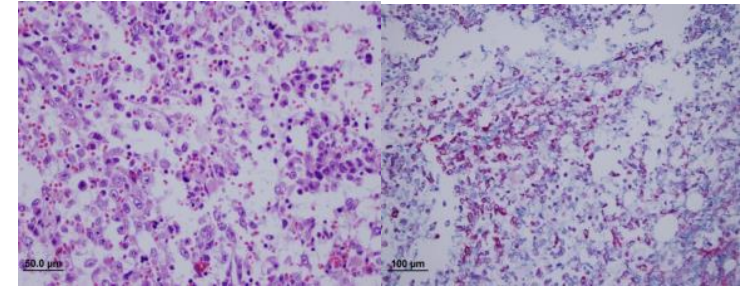

Şekil 7 Kemik iliği imprint örneğinde yoğun olarak belirin pleomorfizm, nükleer atipi ve bazıları tümör dev hücresi formunda atipik neoplastik hücreler.

\section{TARTIŞMA}

Malign melanom, patolojik olarak şeffaf hücreli sarkomlar ve sellüler mavi nevüsler ile karışabilmektedir. Tipik olarak melanoma vimentin, S-100 protein, HMB-45, melan -A, "tyrosinase", ve "microphthalmia transcription factor" ile reaksiyona girer. Bizim vakamız morfolojik ve immünhistokimyasal yönden metastatik malign melanom ile tamamen uyumluydu.

Metastatik malign melanomlu hastaların primer lezyonu \%52 oranla kutanöz lezyondur (7). Bu hastalarda bel ağrısı (en sık), halsizlik, peteşi sık rastlanan bulgulardır (7). Hastamızın 15 gün öncesine kadar başka bir semptomu yoktu. İlk tanı anında cilt lezyonu vardı ve son haftada gövde ve ekstremitelerinde ortaya çıan ekimotik lezyonlarla hastanemize başvurmuştu. Hastamızın şikâyetleri arasında bulunan fokal epileptik bulgular Batsis ve Barry'nin olgularında belirtilmiştir ve nadir semptomlar arasindadir (8).

Metastatik melanom genellikle lenf nodları ve cildi sonra da azalan sıklıkla akciğeri, beyini, karaciğeri, kemiği ve barsakları tutar. Kemik iliği metastazı nadirdir (9). Yaygın kemik iliği tutulumu olan hastalarda pansitopeni beklenir. Ama bizim hastamızda bariz bir lökositoz vardı. Wolff ve arkadaşlarının olgu sunumunda da lökositoz vardı (10) ancak Deepali ve arkadaşlarının sundukları olgu sunumunda lökositoz saptanmamıştı (11). Lökositozun tümör hücrelerince salgilanan sitokin yada diğer mediyatörlere bağlı olduğu düşünülmektedir.

YDIP ile hastaneye yatan malign melanom vakası oldukça nadirdir. Bu hastalarda kemik iliği tutulumu nadirdir. Hematolojik olarak azalan sikl1kta anemi, trombositopeni, pansitopeni ve lökoeritroblastik tablo görülür (3). Hastamızın periferik yaymasında mikroanjiopatik hemolitik anemi bulguları vard1. YDİP'y1 trombositopeni ve hemoliz ile giden diğer hastalıklardan ayırmak gerekir. YDİP'te fibrinojen düzeyinde azalma, fibrin yıkım ürünlerinde ve $\mathrm{D}$-Dimer düzeyinde artmabeklenir. YDİP'te en sık görülen anormal bulgu D-Dimer yüksekliğidir. Protrombin zamanı (PT) ve aktive protirombin zamanında (aPTT) uzama olur. Fibrinojen, akut YDIP'da düşük, fibrinojen yıkım ürünleri yüksektir. Ancak fibrinojen düzeyleri, kendisi bir akut faz reaktanı olduğu için normal çıkabilir. Trombotik trombositopeni ve hemolitik üremik sendromlu hastalarda; trombositopeni ve mikroanjiopatik hemolitik anemi görülmesine karşın koagülasyon faktörlerinde herhangi bir azalma yoktur, PT ve aPTT'de uzama görülmez.Yaygın damar içi pıhtılaşması,bizim olgumuz dışımızda üç olgu sunumunda daha bildirilmiştir.İlk olgu sunumu 1998 yılında yayınlanmış olup Bhagwati ve arkadaşlarına aittir.Bhagwati ve ark.'larıbu tabloyu, bizim vakamızda olduğu gibi, yaygın melanomla ve yaygın hastalık ile ilişkilendirilmiştir (12). Suzuki ve ark.'larıtarafindan yapılanikinci YDİP'liolgu sunumunda ise kendi vakalarının amelanotik melanom vakası olduğunu ve bu tip melanomların daha agresif seyirli olduklarını vurgulamışlardır (13). Son yayın ise 2018 yılına aittir (7) ve bu olgu sunumundaki hasta kombine immünterapi ile tedaviye iyi yanıt vermiştir.

Erken evrelerde cerrahi lokal eksizyon tedavi için yeterliyken ileri evrelerde adjuvan terapiler ve immünoterapi tedavi seçeneklerindendir. İmmünoterapi ile malign melanom olgularında oldukça iyi sonuçlar alınmış olup seçenekler arasında ipilimumab, nivolumab, pembrolizumab, vemurafenibgibi immün sistemi uyaran ilaçlar bulunmaktadır ve bunların kombinasyonları umut vaat edicidir (7).

\section{SONUÇ}

Metastatik malign melanomlu hastaların prognozu kötüdür ve kemik iliği tutulumu yaygın hastalığın bir işaretidir. Şüpheli nevüsü olan bir hastada YDİPolması halinde akla gelmeli ve tedaviye başlamakta geç kalınmamalıdır.

\section{Çıkar çatışmasıı}

Yazarlarımız bir çıkar çatışmalarının olmadığını bildirmektedirler. 


\section{REFERANSLAR}

1. National Cancer Institute, Surveilance, Epidemiology and End Results Program, Annual Report to the Nation on Status of Cancer, Melanoma of the Skin, 2019

2. Rigel DS, Friedman RJ, Kopf AW: The incidence of malignant melanoma in the United States: issues as we approach the 21 st century. J Am Acad Dermatol 1996, 34: 839-847.

3. Parlak A, Şafak E, Mutlu Ç. Melanoma Genel Bakış, Konuralp Tip Dergisi 2014;6(1):22-27

4. S.M. de la Monte SM, Moore GW, Hutchins GM: Patterned distribution of metastases from malignant melanoma in humans. Cancer Res 1983, 43(7):342733.

5. Situm M, Buljan M, Kolic M, Vucic $M$. MelanomaClinical, Dermatoscopical, and Histopathological Morphological Characteristics. Acta DermatovenerologicaCroatica 2014;22(1):1-12

6. Wolf K, Goldsmith LA, Katz SI, et al. Fitzpatrick's Dermatology in General Medicine. 7th ed. USA: Mc Graw Hill Companies; 2008:1134-57.

7. Gbadamosi B, Ezekwudo D, Nayak B, et al. Effective Immunotherapy in Bone Marrow Metastatic
Melanoma Presenting with Disseminated Intravascular Coagulopathy. Case Reports in Immunology Volume 2018, Article ID 4520294, 8

8. Batsis JA, Barry MJ., Metastaticmalignantmelanomapresenting with hypercalcaemia and bonemarrowinvolvement. J Eur Acad Dermatol Venereol. 2006 Apr;20(4):432-4.

9. Serrier $\mathrm{C}$ and François JL. Metastatic malignant melanoma in the bone marrow. Blood 2013 121:721.

10. Wolff JF, Planken EV, den Ottolander GJ: Extreme leucocytosis and splenomegaly in metastasised melanoma. Neth J Med 2004, 62(5):164-7.

11. Jain $D$, Singh $T$, Kumar $N$ and Daga MK. Metastatic malignant melanoma in bone marrow with occult primary site - a case report with review of literature. Diagnostic Pathology 2007, 2:38 doi:10.1186/17461596-2-38.

12. Bhagwati N, Seno R, Dutcher JP, Oleksowicz L: Fulminant metastatic melanoma complicated by a microangiopathic hemolytic anemia. Hematopathol Mol Hematol 1998, 11(2):101-8.

13. Suzuki T., Kusumoto S., Iida S., Tada T., and Mori F., "Amelanotic malignant melanoma of unknown primary origin metastasizing to the bone marrow: A case report and review of the literature," Internal Medicine, vol. 53, no. 4, pp. 325-328, 2014. 